\title{
Estrogen rapidly potentiates amphetamine-induced striatal dopamine release and rotational behavior during microdialysis
}

\author{
Jill B. Becker \\ Psychology Department and Neuroscience Program, The University of Michigan, Ann Arbor, MI 48104-1687 (U.S.A.)
}

(Received 25 May 1990; Revised version received 22 June 1990; Accepted 23 June 1990)

Key words: Amphetamine; Microdialysis; Striatum; Dopamine release; Rotational behavior; Estrogen

Ovariectomy (OVX) of female rats results in a decreased behavioral response to stimulation of the mesostriatal dopamine (DA) system and decreased striatal DA release in vitro. Estrogen replacement restores both behavioral and neurochemical responsiveness. In this report, microdialysis in freely moving rats is used to simultaneously study the behavioral and neurochemical effects of systemic estradiol. OVX rats received a unilateral 6-hydroxydopamine lesion of the substantia nigra and then underwent microdialysis of the intact striatum. Thirty min after a single injection of $5 \mu \mathrm{g}$ estradiol benzoate, amphetamine-induced rotational behavior and striatal DA release are both potentiated, relative to the response of oil-treated control animals.

There is now a substantial body of literature to demonstrate that the gonadal steroid hormones can modulate behavioral and neurochemical indices of mesostriatal dopamine (DA) function. For example, ovariectomy (OVX) results in decreased rotational behavior induced by either electrical stimulation of the mesostriatal bundle or by amphetamine (AMPH) administration $[6,10]$. The behavioral changes observed following OVX are associated with decreased AMPHstimulated DA release in vitro [4].

Treatment of OVX female rats with physiological doses of estrogen potentiates AMPH-stimulated striatal DA release and AMPH-induced rotational behavior [2]. Estrogen treatment also results in increased striatal DA turnover [7] and decreased numbers of DA receptors in striatum [9]. This study was conducted to determine if the neurochemical and behavioral effects of estrogen previously reported can be observed simultaneously, in animals undergoing intrastriatal microdialysis.

Adult female Holtzman rats (Madison, WI) were housed 2-3/cage. The lights were maintained on a 14:10 $\mathrm{h}$ light-dark cycle. Food and water were freely available. All surgery was performed under complete anesthesia (ether or sodium pentobarbital with methoxyflurane)

Correspondence to: Dr. Jill B. Becker, The University of Michigan, Neuroscience Laboratory Building, 1103 E. Huron St., Ann Arbor, MI 48104-1687 according to an approved animal use protocol. Ovariectomized rats received a unilateral 6-hydroxydopamine (6-OHDA) lesion of the substantia nigra (left/right randomized), as previously described [11].

At least 2 weeks after the 6-OHDA lesion, animals were tested for rotational behavior after $1 \mathrm{mg} / \mathrm{kg}$ AMPH. Only rats that turned more than 50 rotations, with greater than $90 \%$ dominance, during each of the three $\mathbf{4 0} \mathrm{min}$ test sessions were included in the experiment. Animals that passed the rotational behavior criterion then received a guide cannula implanted through the skull, aimed at the intact striatum. Coordinates from top of skull at bregma, skull flat were: AP: $+0.5 \mathrm{~mm}$, lateral: $\pm 3.0 \mathrm{~mm}$, ventral: $-1.0 \mathrm{~mm}$. The cannula was secured in place with dental acrylic.

Prior to microdialysis, animals were briefly anesthetized with ether, the stylet was removed from the guide cannula, and the $3 \mathrm{~mm}$ dialysis probe [12] was inserted into the striatum $6.5 \mathrm{~mm}$ from the surface of the skull. All probes were tested in vitro prior to use to determine the rate of DA diffusion across the membrane. The dialysis testing chamber and additional procedures used during dialysis have been previously described [3].

Sample collection began $12-18 \mathrm{~h}$ after the dialysis probe had been implanted. A Ringer's solution flowed through the dialysis probe at $1.5 \mu \mathrm{l} / \mathrm{min}$ and samples were collected at 15 min intervals. After 2 baseline samples were collected, estradiol benzoate (EB; $5 \mu \mathrm{g} / 0.1 \mathrm{ml}$ peanut oil; $n=9)$ or peanut oil $(0.1 \mathrm{ml} ; n=8)$ was admin- 


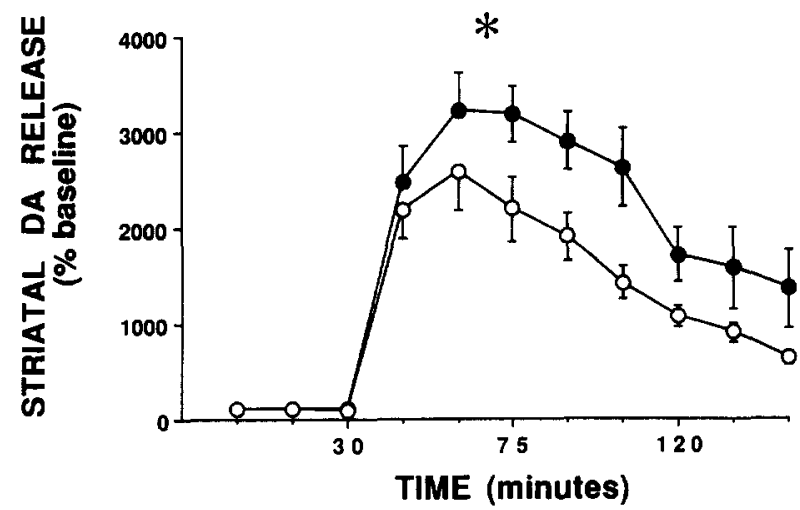

Fig. 1. The AMPH-stimulated increase in striatal extracellular concentrations of DA (expressed as a percent of baseline DA) was signifcantly greater $(P=0.04)$ after EB treatment $(\bullet, n=9)$ than after oil treatment $(O, n=8)$. EB $(5 \mu \mathrm{g})$ or oil were administered after baseline samples were collected at time zero. AMPH $(3.0 \mathrm{mg} / \mathrm{kg})$ was administered $30 \mathrm{~min}$ later (after the sample collected at $30 \mathrm{~min}$ ). The time course data for DA release were analyzed by 2 -way analysis of variance (ANOVA) with repeated measures (hormone treatment $\times$ time). "There was a significant main effect of EB treatment on AMPH-induced DA release $\left(F_{1,15}=4.985, P=0.04\right)$, a significant change over time $\left(F_{7,105}=20.79, P<0.001\right)$, with no interaction $\left(F_{7,105}=0.804, P=0.59\right)$. The two groups did not differ in basal concentrations of extracellular DA (EB group: $1.44 \pm 0.42 \mathrm{pg} / \mu \mathrm{l}$, mean $\pm \mathrm{SEM}$; OIL group: $1.077 \pm 0.17 \mathrm{pg} / \mu \mathrm{l} ; F_{1,15}=0.569, P=0.449$ ).

istered subcutaneously. Samples were collected for an additional $30 \mathrm{~min}$, then AMPH $(3.0 \mathrm{mg} / \mathrm{kg}$; i.p.) was administered and samples were collected at 15 min intervals for an additional $120 \mathrm{~min}$ ( 8 additional intervals).

Concentrations of DA in dialysate were measured with HPLC and coulometric detection [3]. DA concentrations following EB or oil and AMPH stimulation were converted to a percent of the baseline DA concentrations in extracellular fluid. Rotational behavior was monitored by automated rotometers during the intervals after EB or oil treatment and for the entire $2 \mathrm{~h}$ after AMPH administration. Location of the dialysis probe in the striatum was confirmed in $40 \mu \mathrm{m}$ coronal sections.

Thirty min after receiving $5 \mu \mathrm{g} \mathrm{EB}$, the AMPH-stimulated increase in extracellular striatal DA was significantly greater than the response of animals receiving oil (Fig. 1). The potentiation of striatal DA release in the EB group persisted for the entire $2 \mathrm{~h}$ following AMPH treatment $(P=0.04$; see figure legend for additional statistical information). Note that there was no immediate effect of estradiol on basal DA release. In an independent study, $5 \mu \mathrm{g}$ EB had no effect on basal extracellular concentrations of DA in striatum, when basal DA release was monitored for $4 \mathrm{~h}$ following EB (data not shown). Rotational behavior induced by AMPH was also enhanced following EB treatment ( $P<0.02$; Fig. 2). Thus, EB prolonged both the behavioral response to
AMPH as well as the AMPH-stimulated increase in extracellular DA in striatum.

In summary, the rapid effect of a single treatment with a physiological dose of EB on both the behavioral and the neurochemical response to AMPH has been demonstrated simultaneously using microdialysis in freely moving rats. These results confirm previous reports that have demonstrated comparable behavioral and neurochemical effects in independent groups of animals $[2,7,9]$.

The mechanism(s) through which estrogen induces these effects on striatal DA activity remains controversial, since classical receptors for estrogen are not found in substantial numbers in the striatum (see [1] for a discussion). Recent work, however, suggests that even in the absence of these receptors, estrogen can act directly on the striatum to induce changes in striatal DA activity and DA mediated behaviors. For example, bilateral application of $17 \beta$-estradiol to the striatum, but not $17 \alpha$ estradiol, induces an improvement in sensorimotor function in OVX rats [5]. It also prolongs the dorsal immobility response (or carrying response) exhibited by gonadectomized male and female rats when grasped by the skin at the nape of the neck [13]. After the unilateral application of estradiol to the striatum, apomorphine induces postural deviation and lateralized stereotypic behaviors [8]. More conclusively, a recent report from this laboratory has demonstrated that $17 \beta$-estradiol (but not $17 \alpha$-estradiol) can act directly on striatal tissue in vitro

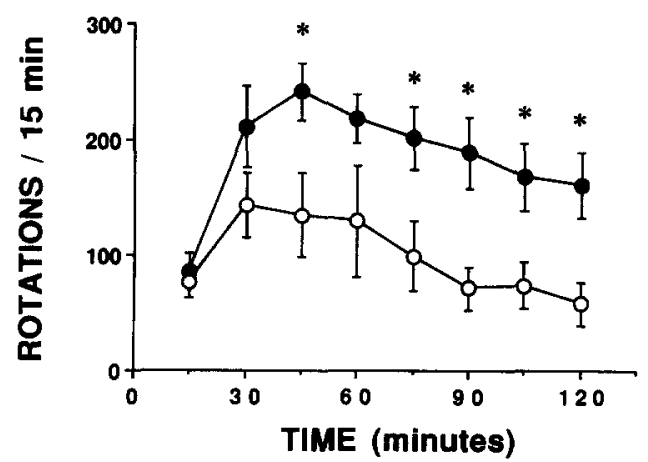

Fig. 2. AMPH stimulated greater rotational behavior in animals receiving $\mathrm{EB}(\Theta, n=8)$ than in animals receiving oil treatment $(\mathrm{O}$, $n=8$ ). (Behavioral data for one EB animal was lost due to a computer malfunction.) Procedures and analysis were the same as indicated in the legend to Fig. 1. There was a significant main effect of EB treatment $\left(F_{1,14}=7.086, \quad P=0.0186\right)$, a significant change over time $\left(F_{7,98}=0.399, \quad P<0.002\right)$, with a trend towards an interaction $\left(F_{7,98}=2.032, P=0.058\right)$. Due to the trend towards an interaction, individual time points were compared. ${ }^{*}$ During these intervals rotational behavior was significantly greater $(P<0.05)$ in animals that received EB than in animals that received oil (Scheffe $F$-test). These two groups of animals did not differ when tested for AMPH-induced rotational behavior without hormone treatment prior to the day of dialysis (EB group: $213 \pm 40$ rotations $/ \mathrm{h}$; OIL group: $140 \pm 33$ rotations $/ \mathrm{h}$; $F_{1,14}=1.98, P=0.181$ ). 
to modulate the striatal DA response to AMPH- and $\mathrm{KCl}$-stimulation and to stimulate striatal DA release [1]. The effect of estrogen on striatal DA mediated behavior and striatal DA release reported here, therefore, may be mediated by a novel mechanism through which estrogen and potentially other steroid hormones can influence neural activity.

This research was supported by USPHS Grants RO1 NS25662 and KO4 NS01056 to J.B.B.

1 Becker, J.B., Direct effect of $17 \beta$-estradiol on striatum: sex differences in dopamine release, Synapse, 5 (1990) 157-164.

2 Becker, J.B. and Beer, M.E., The influence of estrogen on nigrostriatal dopamine activity: behavioral and neurochemical evidence for both pre- and postsynaptic components, Behav. Brain Res., 19 (1986) 27-33.

3 Becker, J.B. and Cha, J., Estrous cycle-dependent variation in amphetamine-induced behaviors and striatal dopamine release assessed with microdialysis, Behav. Brain Res., 35 (1989) 117-125.

4 Becker, J.B. and Ramirez, V.D., Sex differences in the amphetamine stimulated release of catecholamines from rat striatal tissue in vitro, Brain Res., 204 (1980) 361-372.

5 Becker, J.B., Snyder, P.J., Miller, M.M., Westgate, S. A. and Jenuwine, M.J., The influence of estrous cycle and intrastriatal estradiol on sensorimotor performance in the female rat, Pharmacol. Biochem. Behav., 27 (1987) 53-59.
6 Camp, D.M., Becker, J.B. and Robinson,T.E., Sex differences in the effects of gonadectomy on amphetamine-induced rotational behavior in rats, Behav. Neural Biol., 46 (1986) 491-495.

7 Di Paolo, T.,Rouillard, C. and Bedard, P.., 17 beta-Estradiol at a physiological dose acutely increases dopamine turnover in rat brain, Eur. J. Pharmacol., 117 (1985) 197-203.

8 Joyce, J.N. and Van Hartesveldt,C., Estradiol application to one striatum produces postural deviation to systemic apomorphine, Pharmacol. Biochem. Behav., 20 (1984) 575-581.

9 Levesque, D. and Di Paolo, T., Rapid conversion of high into low striatal D2-dopamine receptor agonist binding states after an acute physiological dose of 17 beta- estradiol, Neurosci. Lett., 88 (1988) 113-8.

10 Robinson, T.E., Camp, D.M. and Becker, J.B., Gonadectomy attenuates turning behavior produced by electrical stimulation of the nigrostriatal dopamine system in female but not male rats, Neurosci. Lett., 23 (1981) 203-208.

11 Robinson, T.E., Camp, D.M., Jacknow, D.S. and Becker, J.B., Sex differences and estrous cycle dependent variation in rotational behavior elicited by electrical stimulation of the mesostriatal dopamine system, Behav. Brain Res., 6 (1982) 273-287.

12 Robinson, T.E. and Whishaw, I.Q., Normalization of extracellular dopamine in striatum following recovery from a partial unilateral 6-OHDA lesion of the substantia nigra: a microdialysis study in freely moving rats, Brain Res., 450 (1988) 209-224.

13 Van Hartesveldt, C., Cottrell, G.A. and Meyer, M.E., Effects of intrastriatal hormones on the dorsal immobility response in male rats, Pharmacol. Biochem. Behav., 35 (1990) 307-310. 